\title{
Insulin secretion by rat islet isografts of a defined endocrine volume after transplantation to three different sites
}

\author{
P.T. R.van Suylichem ${ }^{1}$, J.H.Strubbe ${ }^{2}$, H.Houwing ${ }^{2}$, G. H.J. Wolters ${ }^{1}$ and R. van Schilfgaarde ${ }^{1}$ \\ ${ }^{1}$ Department of Surgery, University of Groningen, Groningen and ${ }^{2}$ Department of Animal Physiology, University of Groningen, Haren, \\ The Netherlands
}

\begin{abstract}
Summary. We have analysed the graft function of rat islet isografts of identical and well-defined endocrine volumes after transplantation to three different sites (kidney, liver and spleen). Graft endocrine mass was determined by measuring the total islet volume prior to transplantation and was chosen to be similar to the endocrine volume in the normal adult rat pancreas. Graft function was tested in unanaesthetized, unstressed rats by the responses to glucose infusion and to a meal. All transplanted animals returned to normoglycaemia within one week after transplantation. At one month, basal glucose and insulin levels were similar to controls in rats with grafts to the spleen, but higher in rats with grafts to the kidney or liver. Irrespective of the transplantation site, recipients
\end{abstract}

had higher glucose and lower insulin levels than controls in response to glucose infusion, but in response to a meal these differences from normal were less obvious. Finally, recipients showed both an acute insulin response to glucose infusion as well as a pre-absorptive insulin release after food ingestion, irrespective of the transplantation site. Our findings indicate that the insulin response to glucose infusion and to a meal is quantitatively reduced, but qualitatively intact after transplantation to the kidney, liver or spleen.

Key words: Islet isografts, insulin secretion, kidney, liver, spleen.
Transplantation of islets of Langerhans has been successfully performed in rodents, large laboratory animals and recently also in man. Particularly in rodents, many transplant sites have been studied as to their efficacy in restoring normoglycaemia, normalising glucose tolerance and preventing the occurrence of chronic complications after islet transplantation $[1,2]$. Although normalisation of basal glucose levels can be readily achieved by isogenic islet transplantation in the rodent model, the reports on normalisation of glucose tolerance are not conclusive.

In part this can be explained by differences in endocrine volume of the islet grafts. As islets differ considerably in size $[3,4]$, seemingly similar graft sizes, when defined by the number of transplanted islets, may well represent a considerable difference in the actual number of Beta cells of the islet grafts. In addition, the differing results between the transplant sites have been attributed to efficacy of engraftment after islet transplantation [5] and to the route of venous drainage of insulin by the endocrine graft, i. e. to the portal or to the systemic circulation [6-8]. However, the individual influence either of graft size or of properties related to the graft site on the reported graft function cannot easily be distinguished.
We have therefore determined the metabolic function of rat islet isografts of a specified and predetermined endocrine volume. Islets were transplanted into the portal vein, into the spleen or under the kidney capsule. These sites have previously proven to be highly effective in the rodents. Graft function was tested in unanaesthetized and unstressed freely moving rats [9-11] not only by an intravenous glucose tolerance test (IVGTT) but also by the response to a meal, which is the most physiological stimulus for insulin secretion.

\section{Materials and methods}

\section{Experimental design}

We used isogenic transplants in order to exclude the effect of graft rejection on transplant function. Grafts consisted of clean islets, i. e. without obvious contamination of exocrine tissue, lymph nodes, vessels and ducts. Islet graft endocrine volume was $10 \mu$, which is similar to the endocrine volume of the normal adult rat pancreas $[12,13$. This similarity was verified by determining the insulin content of rat pancreatic tissue both prior to and following standard islet isolation. To this end, the tissue of a rat pancreas was split into two aliquots after ductal distension and chopping, in order to guarantee a uniform 
distribution of islet tissue originating from different parts of the native pancreatic tissue in both aliquots. After insulin extraction, the insulin content was determined both of one aliquot containing native pancreatic tissue and of a sample of islets isolated from the other aliquot. We found the native pancreas to contain $5.27 \pm 0.22 \mathrm{IU}$ of insulin per pancreas, and the isolated islets to contain $5.50 \pm 0.42 \mathrm{IU}$ of insulin per $10 \mu$ lof islet tissue (means $\pm S E M, n=10$ ). The return to normoglycaemia after islet transplantation was verified to be graft dependent by nephrectomy or splenectomy after islet transplantation to the kidney capsule or the spleen, respectively. For obvious reasons, removal of the graft after transplantation to the liver was not performed.

Islets were transplanted to the liver (via the portal vein), to the spleen (by direct injection into the spleen) or to the kidney (under the kidney capsule) in streptozotocin-induced diabetic rats. Transplantation was considered successful when non-fasting blood glucose levels below $8.4 \mathrm{mmol} / 1$ (mean $+2 \times \mathrm{SD}$ of normal controls) were achieved within 3 weeks after transplantation. Graft function was tested by an IVGTT and by a meal test in unanaesthetized and freely moving rats at 1 month post-transplant and compared to similar tests performed in normal control rats.

\section{Animals and induction of diabetes}

Male inbred Albino Oxford $(\mathrm{AO} / \mathrm{G})$ rats were obtained from the Central Animal Laboratory of our Medical Faculty. Body weights of graft recipients, prior to the induction of diabetes, ranged from 290 to $310 \mathrm{~g}$. The body weight of islet donors was âpproximately $350 \mathrm{~g}$. Diabetes was induced by an intravenous injection of streptozotocin (70 mg/kg body weight, Zanosar, a gift from Upjohn Company, Kalamazoo, Mich., USA). Rats were considered diabetic when three or more consecutive non-fasting blood glucose levels exceeding $20 \mathrm{mmol} / \mathrm{l}$ over a period of at least 2 weeks prior to transplantation were found. After transplantation the rats were separately housed for the duration of the experiments (light:dark shift $12 \mathrm{~h}$, lights on from 06.00 hours to 18.00 hours). Animals had free access to water and standard rat chow (containing $53 \%$ carbohydrates, $20 \%$ protein, $5 \%$ fat and $22 \%$ other constituents (minerals, cellulose, water) except for the last $2 \mathrm{~h}$ prior to gluose tolerance testing.

\section{Islet isolation}

The rat islet isolation method as currently applied in our laboratory has been described previously [14]. Briefly, the pancreas was distended by intraductal injection of $10 \mathrm{ml}$ Krebs' Ringer solution containing $25 \mathrm{mmol} / \mathrm{l}$ HEPES and $10 \%$ bovine serum albumin [15]. The pancreas was then excised and cut into small pieces with a pair of scissors. A two stage collagenase (Sigma type XI, $2200 \mathrm{U} / \mathrm{mg}$, St. Louis, Mo., USA) digestion was performed at $37^{\circ} \mathrm{C}$ (collagenase concentrations 1.2 and $0.7 \mathrm{mg} / \mathrm{ml}$, respectively).

Islets were separated from the exocrine tissue using a discontinuous dextran gradient (Sigma industrial grade, $M_{r} 70.000$ ). Further purification was obtained by hand-picking pure islets, i. e. islets without obvious adherent non-endocrine tissue ( $<5 \%$ verified by histology), to eliminate non-separated lymph nodes, vascular and ductal tissue from the islet grafts [14].

Islets were identified with the aid of a dissection microscope and a fluorescence lamp (Bausch and Lomb 31-28-06 and 31-33-66, Rochester, NY, USA). With this illumination, rat islets appear as distinct ochreous bodies, whereas lymph nodes and exocrine tissue are grey. The reliability of this identification method has been confirmed by histology and dithizone staining.

\section{Preparation of the islet grafts}

The total islet volume obtained by the isolation procedure was determined by measuring the islet diameters $[16,17]$, expressed as the mean of two axes, of islets in a $5 \%$ aliquot of the islet suspension.
Subsequently, the total islet volume was calculated whilst assuming the islets to be perfect spheres. Following each islet isolation procedure, one islet graft was prepared by taking an appropriate portion of the islet suspension so as to contain $10 \mu$ l endocrine tissue. Transplantations were performed in a random fashion over the sites studied in order to exclude the influence of possible differences in quality of the isolation procedures.

\section{Transplantation procedures}

Transplantation was performed immediately after the islet isolation. Transplantations into the liver or spleen were performed by direct puncture with a 23 gauge butterfly needle in the portal vein or splenic parenchyma, respectively. During infusion into the spleen, the splenic pedicle was manually occluded in order to reduce possible islet loss to the liver [18]. Transplantation under the kidney capsule was performed at the upper pole by carefully expelling the islets from a polyethylene tube introduced at the lower pole of the kidney. After the transplantation was completed the syringes, butterfly needles and the polyethylene tubes were examined under a dissection microscope to confirm that all islets had been transplanted.

\section{Glucose tolerance tests}

Glucose tolerance was tested by an IVGTT and by the response to a meal. Both tests were performed 4-5 weeks after transplantation. Experimental and control rats were provided with a cardiac catheter implanted via the right jugular vein for blood sampling. A second catheter was implanted into the left jugular vein for the infusion of glucose. This technique allows frequent blood sampling and continuous infusion of fluids in unanaesthetized and freely moving rats [9-11]. Blood loss due to the sampling procedure was replaced by transfusing blood from a normal donor rat at regular intervals. Cannulations were performed 1 week before testing so that the animals could recover from surgery.

IVGTT's were performed by intracardiac infusion of $200 \mathrm{mg}$ glucose at a rate of $10 \mathrm{mg} / \mathrm{min}$. With this technique the unphysiological high peak glucose levels, as seen after a bolus injection, are avoided and glucose profiles follow a more physiological pattern comparable with those observed after a test meal [10]. Blood samples were taken at $10 \mathrm{~min}$ and immediately before glucose administration in order to determine basal values. Subsequent samples were taken at $1,2,3,5,10,15,20,25$ and $30 \mathrm{~min}$ after the beginning of the glucose infusion.

For meal tests, basal values were also determined in two blood samples. An amount of $2 \mathrm{~g}$ rat chow, mixed with $2 \mathrm{ml}$ water, was then put into the cage. The animals had previously been habituated to eat the presented food within $5 \mathrm{~min}$. Blood samples were taken $1,2,3,5,10,15,20,25,30,40$ and 50 min after the animals started to eat.

Glucose tolerance tests could not be performed in all recipient animals either for technical reasons, such as death related to the cannulation surgery or non-patency of the catheters, or due to the refusal to eat more than $75 \%$ (as determined by weight) of the offered test meal within $5 \mathrm{~min}$.

Glucose concentrations were determined in whole blood by a ferricyanide method with a Technicon autoanalyser. Plasma insulin was measured by radioimmunoassay, using rat insulin as a standard.

Glucose tolerance was evaluated by the following parameters. Glucose responses to an IVGTT or to a meal test are presented both as absolute values and as increase above baseline. Also, the area under the curve (AUC) above baseline values was calculated for the first $20 \mathrm{~min}$ of testing $\left(\mathrm{AUC}_{\mathrm{gluc}}(0-20 \mathrm{~min})\right)$. The acute insulin response (AIR) to glucose infusion was defined as the increment of the insulin level in the first minute of the IVGTT. The preabsorptive insulin release (PIR) to a meal was similarly defined with the proviso that a concomitant increase of the blood glucose level was absent. The total amount of insulin secreted during both 
Table 1. Basal glucose and insulin levels of normal control rats and of rats with islet isografts to the kidney, liver or spleen (at 1 month posttransplantation), and the time interval before normoglycaemia was observed

\begin{tabular}{|c|c|c|c|c|}
\hline & $\begin{array}{l}\text { Controls } \\
(n=11)\end{array}$ & $\begin{array}{l}\text { Kidney } \\
(n=6)\end{array}$ & $\begin{array}{l}\text { Liver } \\
(n=5)\end{array}$ & $\begin{array}{l}\text { Spleen } \\
(n=6)\end{array}$ \\
\hline Basal glucose levels (mmol/l) & $5.0 \pm 0.1$ & $5.9 \pm 0.2^{\mathrm{a}, \mathrm{b}}$ & $5.7 \pm 0.2^{\mathrm{a}, \mathrm{c}}$ & $5.1 \pm 0.2^{b, c}$ \\
\hline Basal insulin levels (mU/) & $27.4 \pm 1.4$ & $38.9 \pm 4.0^{\mathrm{a}}$ & $36.9 \pm 1.5^{\mathrm{a}}$ & $29.3 \pm 2.5$ \\
\hline
\end{tabular}

${ }^{\mathrm{a}}$ Significantly different vs controls, ${ }^{\mathrm{b}}$ kidney vs spleen and ${ }^{\mathrm{c}}$ liver vs spleen $(p<0.05)$

Values are mean \pm SEM of $n$ animals

tests was quantified by calculating the area under the curve and above baseline for the first $20 \mathrm{~min}$ of testing $\left(\mathrm{AUC}_{\mathrm{ins}}(0-20 \mathrm{~min})\right.$ ). The insulinogenic index ( $\mathrm{IG}$ ) was defined as the ratio of the mean incremental insulin and the mean incremental glucose levels, each determined at 10,15 and $20 \mathrm{~min}$ [10] and was calculated for each rat individually.

\section{Statistical analysis}

The results are expressed as the mean \pm SEM. Statistical analysis of the results was performed using the unpaired Student's $t$-test or the Mann Whitney U test, when appropriate. A $p$ value $<0.05$ was considered statistically significant.

\section{Results}

\section{Transplant success}

All transplants were successful and all animals became normoglycaemic within 1 week after transplantation. Normoglycaemia was observed first in rats with grafts to the spleen and latest in rats with grafts under the kidney capsule. However, the time lapse between transplantation and normoglycaemia did not differ significantly between the sites (Table 1). Body weights of recipient animals decreased $45 \pm 5 \mathrm{~g}(15 \pm 1 \%)$ after induction of diabetes and initial body weights were regained $12 \pm$ 1 days after transplantation (weight loss and return to pre-streptozotocin levels did not differ significantly for animals with transplantations to kidney, liver or spleen, not shown). Nephrectomy or splenectomy was associated with return to hyperglycaemia in all animals with grafts to the kidney and in $50 \%$ of the animals with grafts to the spleen, respectively. In the other animals with grafts to the spleen, sustained normoglycaemia could be explained in all instances by the presence of small amounts of viable islet tissue in histological sections of the liver. As mentioned before, graft-dependent normoglycaemia was not confirmed in animals with a graft to the liver.

At 1 month post-transplant basal glucose and insulin levels in rats with a transplant to the spleen were similar to controls. This differed for rats with a graft to the liver or under kidney capsule. In these rats, significantly higher basal glucose levels were observed as compared to controls as well as to rats with a transplant to the spleen. The basal insulin levels were higher than those in controls and also than those after transplantation to the spleen, but these latter differences were not statistically significant ( $p=0.10$ and $p=0.05$, respectively).

\section{Intravenous glucose tolerance tests}

Glucose infusion in control animals was associated with an immediate increase of the blood glucose levels that reached a plateau after $15-20 \mathrm{~min}$. The insulin response showed a typical biphasic pattern, i.e. an instantaneous rise of the insulin levels in the first min (AIR) followed by a second phase response after $5 \mathrm{~min}$. The incremental glucose and insulin levels during IVGTT are presented
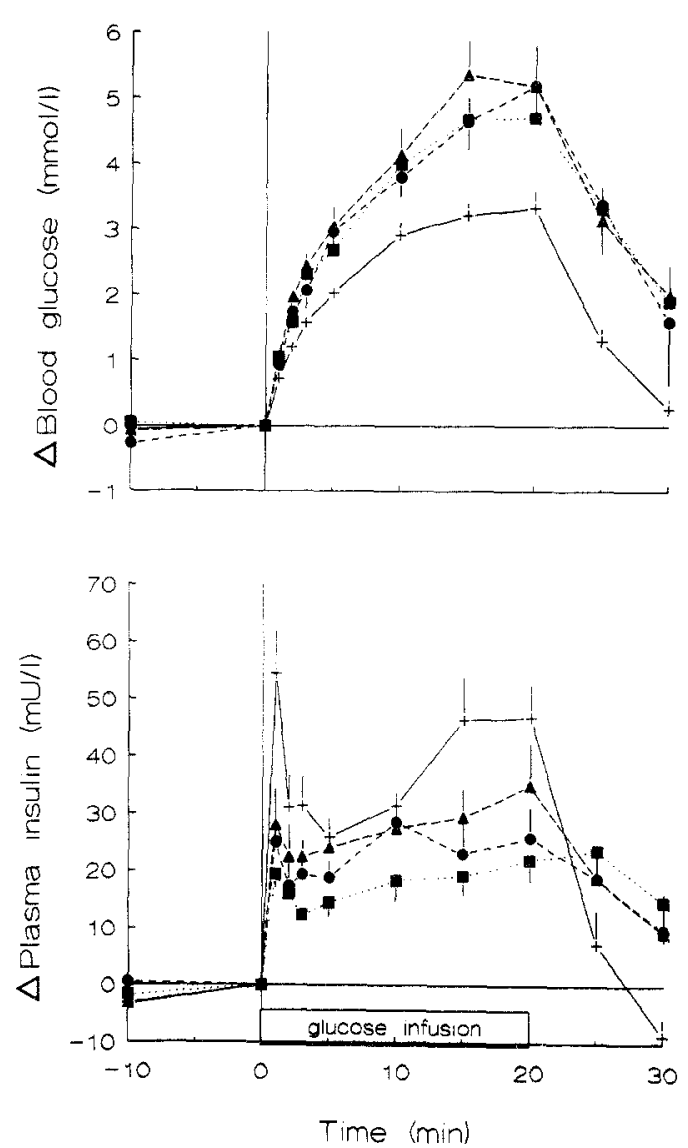

Fig. 1. Glucose and insulin responses to intravenous glucose infusion, presented as increments above basal values, for control animals $(+)$ and for islet grafts to the kidney capsule $(\bullet)$, to the liver $(\Delta)$ and to the spleen ( $\boldsymbol{\square})$. Values describing the characteristics of the curves and the results of statistical analyses are given in Table 2 
Table 2. Glucose and insulin responses to intravenous glucose infusion of normal control rats and of rats with islet isografts to the kidney, liver or spleen

\begin{tabular}{|c|c|c|c|c|}
\hline & $\begin{array}{l}\text { Controls } \\
(n=11)\end{array}$ & $\begin{array}{l}\text { Kidney } \\
(n=4)\end{array}$ & $\begin{array}{l}\text { Liver } \\
(n=5)\end{array}$ & $\begin{array}{l}\text { Spleen } \\
(n=5)\end{array}$ \\
\hline Glucose levels at $20 \mathrm{~min}(\mathrm{mmol} / \mathrm{l})$ & $8.3 \pm 0.2$ & $11.3 \pm 0.4^{\mathrm{a}, \mathrm{b}}$ & $11.0 \pm 0.8^{\mathrm{a}, \mathrm{c}}$ & $9.7 \pm 0.4^{a, b, c}$ \\
\hline Increment above baseline ( $\mathrm{mmol} / \mathrm{l})$ & $3.3 \pm 0.2$ & $5.2 \pm 0.6^{\mathrm{a}}$ & $5.2 \pm 0.6^{\mathrm{a}}$ & $4.7 \pm 0.4^{\mathrm{a}}$ \\
\hline $\operatorname{AIR}(\mathrm{mU} / 1)$ & $54.4 \pm 7.8$ & $25.0 \pm 4.3^{\mathrm{a}}$ & $28.0 \pm 6.4^{a}$ & $19.4 \pm 2.0^{\mathrm{a}}$ \\
\hline $\operatorname{AUC}_{\mathrm{ins}}(0-20 \mathrm{~min})\left(\mathrm{mU} \cdot 1^{-1} \cdot \mathrm{min}\right)$ & $728 \pm 88$ & $459 \pm 86$ & $540 \pm 87$ & $346 \pm 50^{\mathrm{a}}$ \\
\hline $\mathrm{IG}(\mathrm{mU} / \mathrm{mmmol})$ & $8.37 \pm 0.62$ & $5.90 \pm 0.31^{\mathrm{a}}$ & $6.30 \pm 0.49^{\mathrm{a}}$ & $5.10 \pm 0.66^{\mathrm{a}}$ \\
\hline
\end{tabular}

${ }^{a}$ Significantly different vs controls, ${ }^{b}$ kidney vs spleen and ${ }^{c}$ liver vs spleen $(p<0.05)$.

Values are mean \pm SEM of $n$ animals.

AUC, Area under the curve; AIR, acute insulin response; IG, insulinogenic index

Table 3. Glucose and insulin responses to a meal by normal control rats and by rats with islet isografts to the kidney, liver or spieen

\begin{tabular}{|c|c|c|c|c|}
\hline & $\begin{array}{l}\text { Controls } \\
(n=9)\end{array}$ & $\begin{array}{l}\text { Kidney } \\
(n=4)\end{array}$ & $\begin{array}{l}\text { Liver } \\
(n=4)\end{array}$ & $\begin{array}{l}\text { Spleen } \\
(n=3)\end{array}$ \\
\hline Glucose levels at $20 \mathrm{~min}(\mathrm{mmol} / \mathrm{l})$ & $6.0 \pm 0.1$ & $7.5 \pm 0.2^{a, 0 . c c}$ & $6.5 \pm 0.2^{\mathrm{a}, \mathrm{b}}$ & $6.5 \pm 0.2^{\mathrm{a}, \mathrm{c}}$ \\
\hline Increment above baseline $(\mathrm{mmol} / \mathrm{l})$ & $1.1 \pm 0.1$ & $1.7 \pm 0.2^{\mathrm{a}}$ & $1.1 \pm 0.2$ & $1.2 \pm 0.1$ \\
\hline $\operatorname{PIR}(\mathrm{mU} / \mathrm{l})$ & $22.1 \pm 7.0$ & $11.1 \pm 2.2$ & $11.0 \pm 4.5$ & $6.0 \pm 2.2$ \\
\hline $\operatorname{AUC}_{\mathrm{min}}(0-20 \mathrm{~min})\left(\mathrm{mU} \cdot \mathrm{I}^{-1} \cdot \mathrm{min}\right)$ & $506 \pm 48$ & $485 \pm 87$ & $360 \pm 104$ & $499 \pm 29$ \\
\hline $\mathrm{IG}(\mathrm{mU} / \mathrm{mmol})$ & $9.17 \pm 0.64$ & $10.59 \pm 0.95$ & $9.85 \pm 1.24$ & $10.66 \pm 1.54$ \\
\hline
\end{tabular}

${ }^{\mathrm{a}}$ Significantly different vs controls, ${ }^{\mathrm{b}}$ kidney vs spleen and ${ }^{\mathrm{c}}$ kidney vs spleen $(p<0.05)$.

Values are mean \pm SEM of $n$ animals.

AUC, Area under the curve; PIR, preabsorptive insulin release; IG, insulinogenic index

in Figure 1. The quantifications and calculations describing the characteristics of these curves are given in Table 2.

For all transplant sites, the glucose plateau levels at $20 \mathrm{~min}$ (both absolute and incremental) were significantly higher than in the controls. Mutual comparison of the transplant sites showed that the increments did not differ, although the absolute level attained with grafts to the spleen was lower than with grafts to the kidney and liver. After transplantation, the $A U C_{\text {gluc }}(0-20 \mathrm{~min})$ was significantly higher than in controls, but the $\mathrm{AUC}_{\text {gluc }}(0-20 \mathrm{~min})$ did not differ between the transplant sites.

An AIR to the glucose infusion was seen in all transplanted animals, but the AIR's were significantly lower after transplantation than in controls. The total insulin secretion $\left(\mathrm{AUC}_{\mathrm{ins}}(0-20 \mathrm{~min})\right)$ was also considerably lower in transplanted animals than in controls, but these differences were statistically significant only with grafts to the spleen. The IG was significantly lower after transplantation for all sites. The AIR's, the $\mathrm{AUC}_{\text {ins }}(0-20 \mathrm{~min})$ 's and the IG's were similar for all graft sites.

\section{Meal tests}

In the controls, a significant increase of the blood glucose levels above basal values was seen 3 min after the beginning of the meal test and glucose levels reached a maximum after $15-20 \mathrm{~min}$. A PIR i.e. significant increase of the plasma insulin level preceding an elevation of the glucose level, was observed at 1 min. The maximum plasma insulin level was reached at $20 \mathrm{~min}$. The incremental glucose and insulin levels during the meal test are shown in Figure 2. The quantifications and calculations describing the characteristics of these curves are given in Table 3.

In the animals which had undergone transplantation maximum glucose levels were significantly higher than in controls when expressed as absolute values. However, the incremental maximum glucose levels were significantly higher than those in controls only for grafts under the kidney capsule. When the glucose responses of transplanted animals were mutually compared, absolute glucose levels were significantly higher with grafts under the kidney capsule than with grafts to the liver or spleen, but the increments were similar. Although Figure 2 suggests a higher $\mathrm{AUC}_{\text {gluc }}(0-20 \mathrm{~min})$ in transplanted animals than in controls, the differences were not statistically significant (Table 3).

A PIR was seen for all sites. Although the PIR in transplanted animals was $50 \%$ or less than in controls, levels of statistical significance were not reached due to the large variation of the individual responses. As can be seen in Figure 2, insulin secretion after transplantation was lower during the first $10 \mathrm{~min}$ of the meal test as compared to controls. However, the $\mathrm{AUC}_{\mathrm{ins}}(0-20 \mathrm{~min})$ of grafts under the kidney capsule and to the spleen was similar to that in controls. The mean $\mathrm{AUC}_{\mathrm{ins}}(0-20 \mathrm{~min})$ of grafts to the liver was $30 \%$ lower than in controls, but this difference was not statistically significant. The IG indices were slightly elevated after transplantation as compared to controls. 

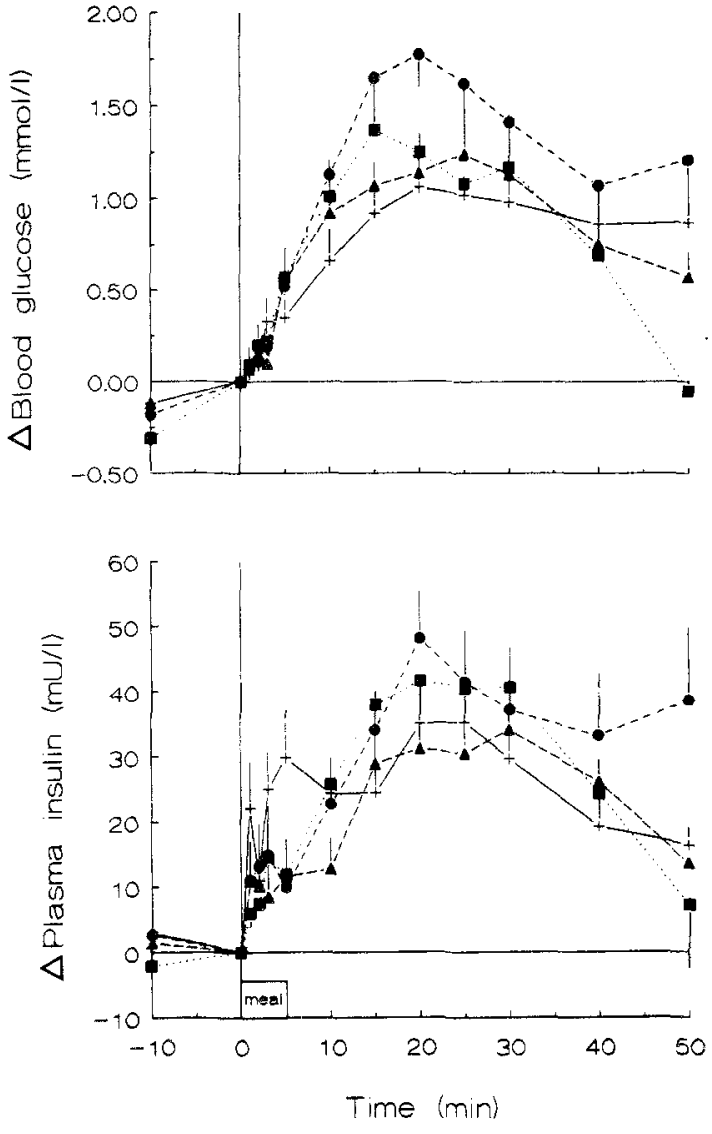

Fig. 2. Glucose and insulin responses to a standard meal, presented as increments above basal values, for control animals $(+)$ and for islet grafts to the kidney capsule ( $)$, to the liver $(\boldsymbol{\Delta})$ and to the spleen ( $\mathbf{a})$. Values describing the characteristics of the curves and the results of statistical analyses are given in Table 3. (please note the difference in scale of the incremental glucose values of Fig. 1 and Fig. 2)

\section{Discussion}

Glucose tolerance was not completely normalized when tested 1 month after transplantation, despite the fact that the transplanted endocrine volume was similar to that of the normal adult rat pancreas [12,13]. Basal glucose and insulin levels in animals with grafts to the spleen were similar to those in controls, but they were significantly higher in animals with grafts to the liver and to the kidney. The increased basal insulin levels seen after transplantation to the kidney can be attributed to the absence of the first-pass insulin extraction by the liver as a consequence of systemic instead of portal venous drainage [6, 19-21]. Hyperinsulinaemia, after transplantation to the liver, cannot be attributed to an absent first-pass extraction of insulin, but there is substantial evidence to suggest that this extraction is quantitatively reduced. First, it has been demonstrated that the insulin extraction rate decreases when increasing insulin concentrations are presented to the hepatic tissue [22,23]. Second, Griffith et al. [24] have shown that the glycogen content of hepatocytes is higher in hepatocytes in the direct vicinity of transplanted islets than in more distant liver tissue, indicating high insulin concentrations in the peri-insular areas. Therefore, hyperinsulinaemia after transplantation to the liver can be interpreted as the consequence of a reduced extraction by only a part of the liver tissue [25]. This is associated with a reduced storage of glucose in the liver, resulting in slightly elevated basal glucose levels.

In response to glucose infusion, higher glucose levels and lower insulin levels were observed in all transplanted animals than in controls, irrespective of the transplantation site. The total amount of insulin secretion was also reduced. This appears to be mainly caused by a quantitatively reduced first phase insulin response, since incremental glucose levels in transplanted animals had increased above those of controls in the first $5 \mathrm{~min}$, while the slope of the curves was roughly similar to those of the controls for the remaining intravenous test period. Obviously, there is a quantitatively reduced secretory capacity of the grafts, as further substantiated by reduced IG indices. This suggests that the volume of functioning Beta-cell tissue at 1 month after transplantation is insufficient, although the graft endocrine volume prior to transplantation was similar to that of the normal rat pancreas. Hypothetically, there are two causative factors. Most likely there is incomplete engraftment of the transplanted tissue in all three transplantation sites. In addition, there may be a reduced viability of some islet cells following the isolation procedure.

The results showed less deviation from normal controls when a meal, rather than a glucose infusion, was used for testing graft performance. In fact, the response of islet grafts appears to be quite efficient when physiologically challenged. This can be attributed to the so-called 'incretin effect', i.e. the release of gastro-intestinal peptides in response to a meal which enhances insulin secretion [26-28].

Irrespective of the transplantation site, insulin responses to intravenous testing always showed an AIR, and insulin responses to a meal test always showed a PIR. This indicates that, in spite of quantitative deviations, the insulin response was qualitatively intact with both intravenous and with oral testing.

A first phase insulin response to intravenous glucose loading has previously been demonstrated by others for islet grafts to the liver $[18,29,30]$, but was absent with grafts to the kidney [11] or spleen [18]. These studies used bolus injections and the subsequent very fast rise of the insulin levels interferes with visual discernment between the acute and secondary insulin response. With our method of glucose infusion, both responses can be recognized more easily, which may explain why we could demonstrate the presence of an AIR for all three transplantation sites. This finding is also more compatible with the response expected, since there is no reasonable explanation for a first phase insulin response restricted only to isolated islets in vitro $[28,31,32]$ and to the liver as a transplant site.

The PIR was found to be lower after islet transplantation than in controls. As expected, blood glucose levels increased above the levels in controls within the first $5 \mathrm{~min}$ of the meal test. Thereafter, the glucose curves in grafted animals paralleled the glucose curves in controls and the increase in insulin levels exceeded the increase observed 
in control animals. This indicates that the secondary insulin response to a meal is intact.

This is the first study in which a PIR was found after islet transplantation. The absence of a PIR after islet transplantation to the kidney [1], liver [33] or spleen [34] as reported in previous studies, was attributed to denervation of the islet graft, since the PIR is assumed to be of parasympathetic vagal origin. Nevertheless, others have histologically demonstrated ingrowth of nerves into islets by 10 days after transplantation to the liver [24]. However, with islet grafts to the spleen [35] or to the kidney [36], ingrowth was not observed earlier than at 4 weeks and at 14 weeks after transplantation, respectively. Furthermore, these nerves were identified to be of sympathetic instead of parasympathetic origin. Since our animals were tested at 4 to 5 weeks after transplantation, this suggests that another mechanism, probably under neural control and involving gastro-intestinal hormones, is responsible for the PIR as observed in our experiments.

In conclusion, our study indicates that the metabolic response of islet grafts is quantitatively reduced, irrespective of the transplantation site. It also indicates that the metabolic response is qualitatively intact. This suggests that normal glucose regulation can be obtained by a larger mass of engrafted islet tissue. It is not possible to decide conclusively on the preferable transplantation site, since none was superior to another. However, grafts to the spleen were found to approximate normal metabolic function somewhat more than grafts to the kidney or to the liver.

Acknowledgements. The authors wish to thank Ms G. J. van Empel, Ms K. M. A. Fränkel, Ms C. A. Hofstee and Mr. K. A. Scheepstra for performing the glucose tolerance tests, Ms M.W. A. Vonk and Ms A.M.A. Weemaes for their excellent technical assistance and Ms C. Schotpoort-Ostermeier for typing this manuscript. This study was supported by a grant from the Diabetes Research Fund of The Netherlands.

\section{References}

1. Sutherland DER (1981) Pancreas and islet transplantation 1. Experimental studies. Diabetologia 20: 161-185

2. Gray DWR, Morris PJ (1987) Developments in isolated pancreatic islet transplantation. Transplantation 43: 321-331

3. Wolters GHJ, Van Suylichem PTR, Pasma A, Van Schilfgaarde R (1990) Morphometric analysis of the endocrine pancreas of rats, normal and hyperglycaemic mice. Netherlands J Med 36: A1

4. Fritschy WM, Van Straaten JFM, De Vos P, Wolters GHJ, Van Schilfgaarde R (1991) The efficacy of intraperitoneal pancreatic isografts in the reversal of diabetes in rats. Transplantation 52: $777-783$

5. Mellgren A, Schnell Landström AH, Petersson B, Andersson A (1986) The renal subcapsular site offers better growth conditions for transplanted mouse pancreatic islet cells than the liver or spleen. Diabetologia 29: 670-672

6. Reece-Smith H, McShane P, Morris PJ (1982) Glucose and insulin changes following a renoportal shunt in streptozotocin diabetic rats with pancreatic islet isografts under the kidney capsule. Diabetologia 23: 343-346
7. Cuthbertson RA, Mandel TE (1986) A comparison of portal versus systemic venous drainage in murine foetal pancreatic islet transplantation. Aust J Exp Biol Med Sci 64: 175-184

8. Lück R, Klempnauer J, Ehlerding G, Kühn K (1990) Significance of portal venous drainage after whole-organ pancreas transplantation for endocrine graft function and prevention of diabetic nephropathy. Transplantation 50: 394-398

9. Strubbe JH, Steffens AB, De Ruiter L (1977) Plasma insulin and the time pattern of feeding in the rat. Physiol Behav 18: 81-86

10. Strubbe JH, Bouman PR (1978) Plasma insulin patterns in the unanesthetized rat during intracardiac infusion and spontaneous ingestion of graded loads of glucose. Metabolism 27: 341351

11. Strubbe JH, Van Wachem P (1981) Insulin secretion by the transplanted neonatal pancreas during food intake in fasted and fed rats. Diabetologia 20:228-236

12. Freie HMP, Pasma A, Bouman PR (1975) Quantitative analysis of pancreatic islet development and insulin storage in foetal and newborn rat. Acta Endocr 80: 657-666

13. Van Suylichem PTR, Wolters GHJ, Van Schilfgaarde R (in press) Peri-insular presence of collagenase during islet isolation procedures. J Surg Res (in press)

14. Van Suylichem PTR, Wolters GHJ, Van Schilfgaarde R (1990) The efficacy of density gradients for islet purification: a comparison of seven density gradients. Transplant Int 3: 156 161

15. Wolters GHJ, Van Suylichem PTR, Van Deijnen JHM, Van Schilfgaarde R (1990) Factors influencing the isolation process of islets of Langerhans. In: Federlin K, Bretzel RG, Hering BJ (eds)Methods in islet transplantation research. Horm Metab Res 25 [Suppi]: 20-26

16. Reaven EP, Gold G, Walker W, Reaven GM (1981) Effect of variations in islet size and shape on glucose-stimulated insulin secretion. Horm Metab Res 13:673-674

17. Ricordi C, Gray DWR, Hering BJ et al. (1990) Islet isolation assessment in man and large animals. Acta Diabetol Lat 27:185-195

18. Feldman SD, Hirshberg GE, Dodi G et al. (1977) Intrasplenic islet isografts. Surgery 82: $386-394$

19. Lugagne PM, Reach G, Houry S, Peuchemaure M, Rouchette J, Huguier M (1989) Portal versus peripheral venous drainage in segmental pancreatic transplantation in diabetic rats. Transplantation 47: 420-423

20. Van der Burg MPM, Gooszen HG, Guicherit OR et al. (1989) Contribution of partial pancreatectomy, systemic hormone delivery, and duct obliteration to glucose regulation in canine pancreas: importance in pancreas transplantation. Diabetes 38 : 1082-1089

21. Diem P, Abid M, Redmon JB, Sutherland DER, Robertson RP (1990) Systemic venous drainage of pancreas allografts as independent cause of hyperinsulinemia in type 1 diabetic recipients. Diabetes 39: 534-540

22. Honey RN, Price S (1979) The determinants of insulin extraction in the isolated perfused rat liver. Horm Metab Res 11: 111 117

23. Eaton RP, Allen RC, Schade DS (1983) Hepatic removal of insulin in normal man: dose response to endogenous insulin secretion. J Clin Endocrinol Metab 56: 1294-1300

24. Griffith RC, Scharp DW, Hartman BK, Ballinger WF, Lacy PE (1977) A morphological study of intrahepatic portal-vein islet isografts. Diabetes 26: 201-213

25. Pipeleers-Marichal M, Pipeleers DG, Cutler J, Lacy PE, Kipnis D (1976) Metabolic and morphologic studies in intraportal islet transplanted rats. Diabetes 25:1041-1051

26. Berthoud HR (1984) The relative contribution of the nervous system, hormones, and metabolites to total insulin response during a meal in rats. Metabolism 33: 18-25

27. Creutzfeldt W, Ebert R (1985) New developments in the incretin concept. Diabetologia 28: 565-573

28. Siegel EG, Creutzfeldt W (1985) Stimulation of insulin release in isolated rat islets by GIP in physiological concentrations and its relation to islet cyclic AMP content. Diabetologia 28: 857-861 
29. Brömme HJ, Hahn HJ, Blech W (1988) Biphasic release of islets of Langerhans after their transplantation into the liver in rats. Horm Metab Res 20: 138-140

30. Blech W, Cossel L, Hahn HJ et al. (1990) Morphological alterations and biochemical reactions of syngeneic pancreatic islets transplanted into the liver of diabetic. Lewis rats. Horm Metab Res 25 [Suppl]: 148-153

31. Lacy PE, Walker MM, Fink CJ (1972) Perifusion of isolated rat islets in vitro: participation of the microtubular system in the biphasic release of insulin. Diabetes 21: 987-998

32. Sando H, Grodsky GM (1973) Dynamic synthesis and release of insulin and proinsulin from perifused islets. Diabetes 23: 354360

33. Trimble ER, Berthoud HR, Siegel EG, Jeanrenaud B, Renold AE (1981) Importance of cholinergic innervation of the pancreas for glucose tolerance in the rat. Am J Physiol 241: E337E341

34. Kakizaki K, Basadonna G, Merrell RC (1986) Neural regulation of heterotopic islets of Langerhans. Surgery 100: 997-1002
35. Madureira MLC, Adolfo A. Dias J, Sebe M, Carvalhais HA, Von Hafe P (1985) Reinnervation of the endocrine pancreas after autotransplantation of pancreatic fragments in the spleen of the dog: a morphofunctional study. World J Surg 9:335-347

36. Korsgren O, Andersson A, Jansson L, Sundler F (1991) Reinnervation of transplanted mouse pancreatic islets. Transplant Proc 23: 750-751

Received: 27 January 1992

and in revised form: 1 June 1992

Dr.P.T.R.van Suylichem

Surgical Research Laboratory

Department of Surgery

University of Groningen

Bloemsingel 1

NL-9713 BZ Groningen

The Netherlands 